\title{
Ausstellung „Orages de Papier“ in Paris
}

\section{Von Hans-Christian Pust}

Am 26. Oktober 2010 wurde in Paris die Ausstellung „Orages de Papier - La Grande Guerre des médias“ eröffnet. Die Bibliothek für Zeitgeschichte hat diese Ausstellung zusammen mit der Bibliothèque nationale et universitaire de Strasbourg (BNU), der Bibliothèque de Documentation Internationale Contemporaine (BDIC) in ParisNanterre und der Bibliothèque nationale de France $(\mathrm{BnF})$ erarbeitet. Alle vier Institutionen haben zu der Ausstellung Exponate aus ihren Kriegssammlungen beigesteuert, die im Ersten Weltkrieg angelegt wurden.

Die Ausstellung war 2008 und 2009 schon in Straßburg und in Stuttgart zu sehen. In Paris wird sie in den Ausstellungsräumen der BDIC im Hôtel National des Invalides gezeigt.

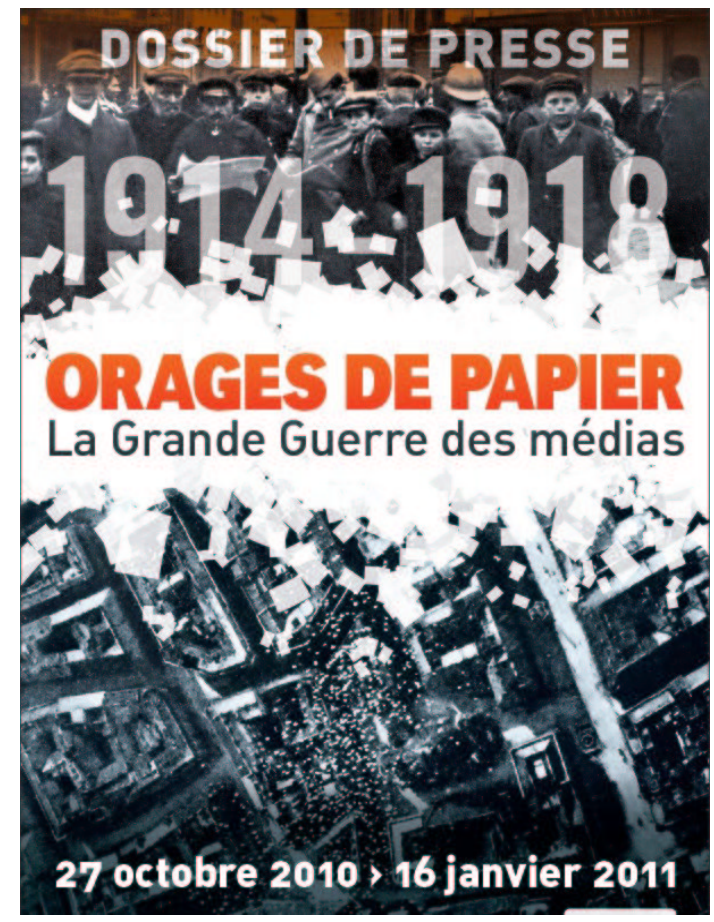

Plakat zur Ausstellung „Orages de Papier“ in Paris

Die Ausstellung beginnt mit einer Abteilung zu den verschiedenen Kriegssammlungen selbst. Hier findet sich beispielsweise ein Porträt von Louise Leblanc. Zusammen mit ihrem Mann Henri gründete sie 1915 eine private Kriegssammlung in Paris, aus der die heutige BDIC hervorging. Die BfZ zeigt in diesem Bereich die Büste ihres Gründers Richard Franck. 


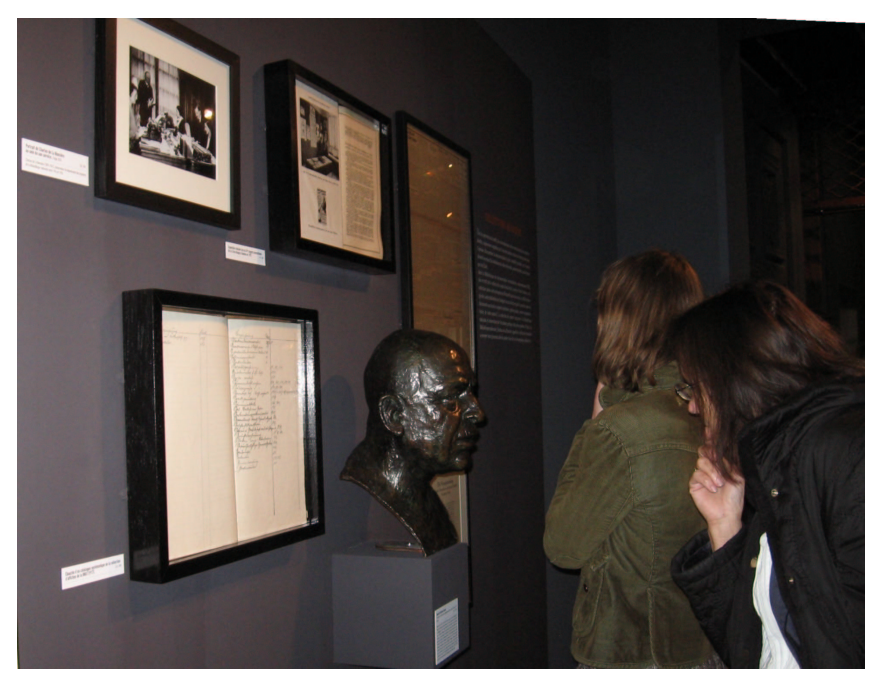

Exponate zu den vier verschiedenen Kriegssammlungen am Beginn der Ausstellung

In der Ausstellung sind Objekte unterschiedlicher Medienarten zu sehen, die in der damaligen Kriegspropaganda genutzt wurden und die dann in die verschiedenen Kriegssammlungen gelangten: Neben Plakaten und Postkarten sieht man hier auch Flugblätter, Maueranschläge, Fotografien und Feldzeitungen. Daneben werden jedoch auch private Quellen wie Tagebücher und Feldpostbriefe präsentiert. In der Pariser Ausstellung besteht sogar die Möglichkeit, sich einzelne Textpassagen aus diesen Quellen anzuhören. Diese Audio-Stationen ermöglichen in einer anderen Abteilung der Ausstellung auch das Anhören von Chansons aus der damaligen Zeit.

An einer besonderen Station haben die Besucher daneben die Möglichkeit, in einigen Quellen virtuell zu blättern und sich somit eingehender mit einzelnen Quellen zu beschäftigen.

Sehr eindrucksvoll wirken die deutschen und französischen Kriegsplakate, die alle im Original gezeigt werden. Einige dieser Plakate stammen aus den Beständen der BfZ, die BDIC in Paris besitzt allerdings auch selbst zahlreiche deutsche Quellen aus dem Ersten Weltkrieg.

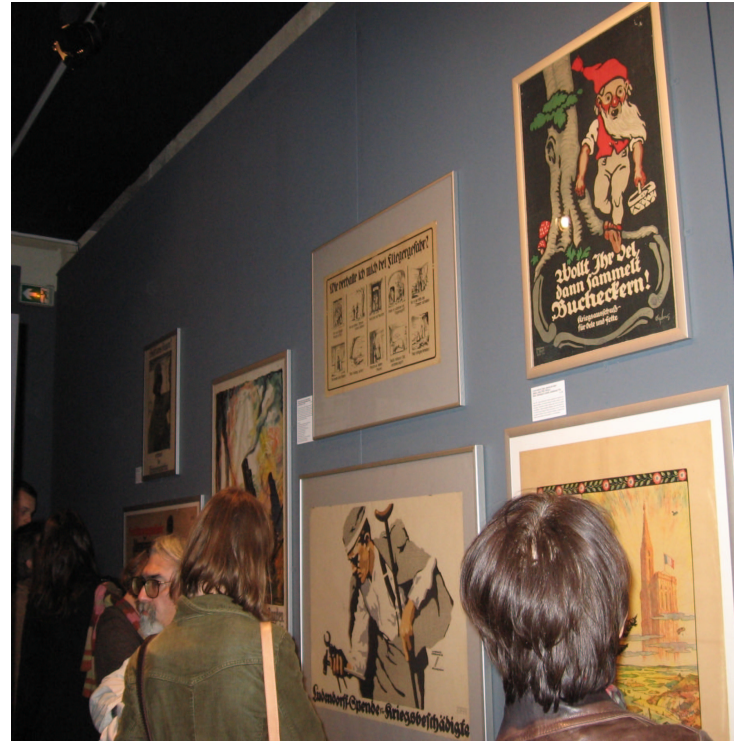

Präsentation deutscher und französischer Kriegsplakate 
Die Maueranschläge - Bekanntmachungen und Verordnungen in rein schriftlicher Form - werden, wie schon in Straßburg und Stuttgart, auf eine Plexiglaswand montiert gezeigt, was ihre ursprüngliche Verwendung sehr schön nachempfindet.

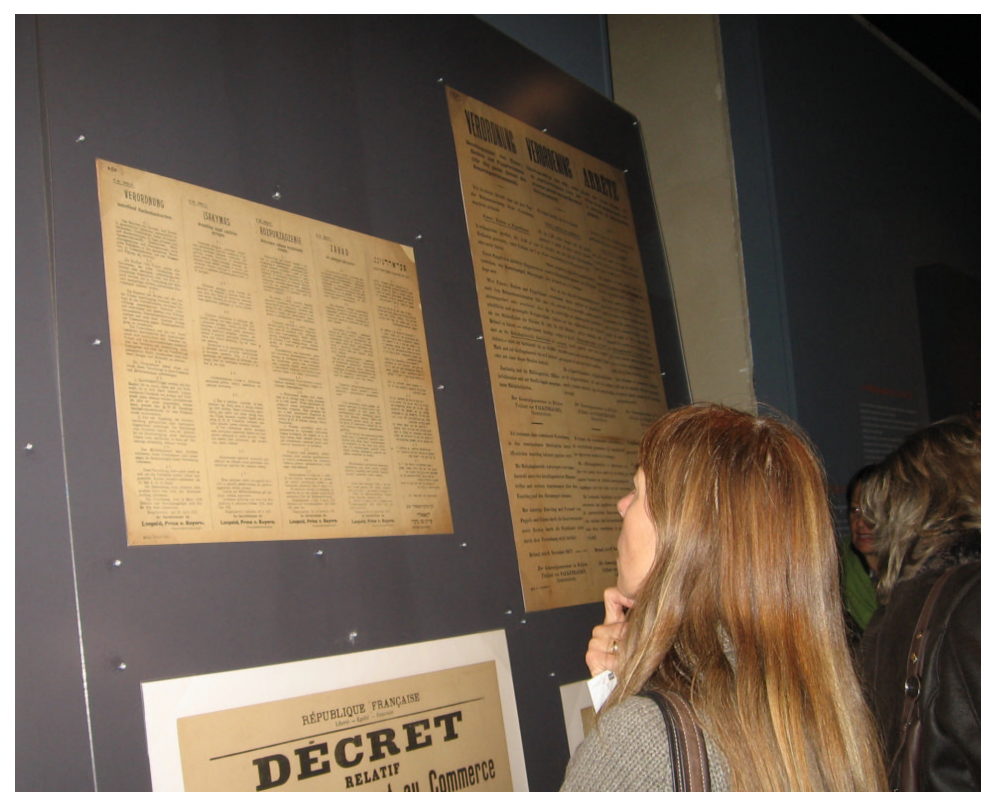

Präsentation deutscher und französischer Maueranschläge

Besonders eindrucksvoll erscheint in der Ausstellung ein recht großer, sehr dunkel gehaltener Raum, in dem Fotografien ausgestellt sind, die in dieser Umgebung außerordentlich gut zur Geltung kommen. In einem anderen Raum ist eine Installation einer „Bücherstube“ aufgebaut, die die „Flut" von Büchern und Broschüren veranschaulichen soll, die in der Zeit des Ersten Weltkriegs in allen kriegführenden Ländern veröffentlicht wurden.

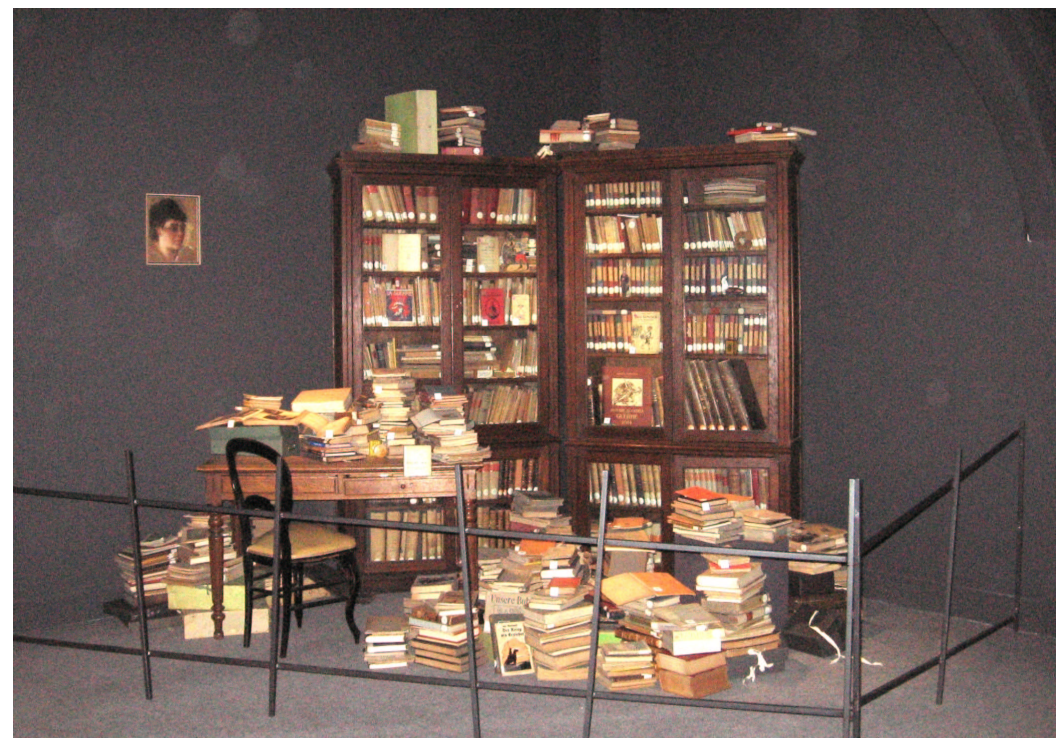

Installation zur „Bücherflut“ des Ersten Weltkrieges 
Daneben sind in einer besonderen Abteilung noch Gemälde von „Kriegsmalern“ aus der Zeit des Ersten Weltkriegs zu sehen. Hier besitzt insbesondere die BDIC eine umfangreiche Sammlung, aus der einige Beispiele im Original gezeigt werden. In Stuttgart konnten aufgrund der konservatorischen Verhältnisse nur Kopien dieser Gemälde gezeigt werden.

Bei der Ausstellungseröffnung im recht engen Eingangsbereich der Ausstellung sprachen als Vertreter der beteiligten Institutionen: Bernadette Madeuf, die Präsidentin der „Université de Paris Ouest Nanterre La Défense“, zu der die BDIC organisatorisch gehört, Valérie Tesnière, die Direktorin der BDIC, Albert Poirot als Leiter der BNU und Prof. Gerhard Hirschfeld als Leiter der BfZ.

Die Ausstellung wird in Paris zum letzten Mal zu sehen sein, und zwar noch bis zum 16. Januar 2011. Damit endet die sehr erfolgreiche mehrjährige Zusammenarbeit der BfZ/WLB mit den drei französischen Bibliotheken im Rahmen dieses Ausstellungsprojekts. 